M AX - PLAN CK-INSTITUT FÜR WISSENSCHAFTSGESCHICHTE

Max Planck Institute for the History of Science

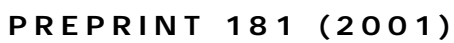

Oscar J oão Abdounur

Ratios and music in the late Middle Ages:

a preliminary survey 


\title{
RATIOS AND MUSIC IN THE LATE MidDle AgES: A PRELIMINARY SURVEY ${ }^{1}$
}

\author{
Oscar João Abdounur ${ }^{2}$ \\ Max Planck Institut für Wissenschaftsgeschichte \\ Universidade de São Paulo
}

\section{INTRODUCTION}

In this essay, I would like to bring out an epistemological understanding of the participation of ratio in theoretical music in the late Middle Ages, and thereby to recover the origin of ratio in the attempts to rationalize and systematize the theory of music in the Pythagorean School, which subsequently contributed to the development of the pre-Eudoxan mathematical theory of proportions - a theory that, in its turn, left behind it in the Eudoxan theory of proportions presented in book V of Euclid's The Elements musical traces that are manifested not only in terminology and discourse but in operations whose underlying structure evokes a strong resonance with the Pythagorean theory of music. These traces of Eudoxan theory in Euclid are, furthermore, such that they can be understood without reference to music yet are at the same time meaningful in musical terms. Such similarities persisted in the treatment of ratios up to the 17th century and played an important role in forming a non-arithmetical tradition in such treatments which eventually catalyzed the process of arithmetization - a process ironically propelled by the need for a solution of emergent theoretical problems in the early Renaissance pertaining to music.

Such a theme suggests a study of the construction and reinterpretation undergone by the concept of ratio, from Ancient Greece until the period in question. The reflection in the Middle Ages and in the Renaissance of procedures in which is evinced such a striking similarity between the sciences of music and mathematics, taken together with the gradual reinterpretation of different theories of ratios of a geometrical and/or arithmetical nature with occasional musical vestiges, should also prove helpful in an inquiry into the origin of the analogies that came to exist between the two sciences of mathematics and music.

\footnotetext{
1 To be published in: Vendrix, Philippe (ed.). Musique et mathématique à la Renaissance-Centre d'Études Supérieures de la Renaissance.Université François Rabelais.

2 I am very grateful to Peter Damerow, Jürgen Renn and Urs Schoepflin from Max Planck Institute for providing me with essential assistance to my research, as well as, to Brian Fuchs, for correcting my English.
} 
This essay investigates theories of ratio and their interrelationship with music from Antiquity to the period especially between the 12th and the 16th centuries in Europe. It seeks to make clear the reflection of the aforementioned similarities in the early modern period, as they were gradually re-oriented, and thus transformed, albeit irregularly, into similar arithmetic structuresstructures ultimately dictated by the same practical needs that were responsible for bringing together so many other aspects of the very complex process associated with the emergence of an arithmetical theory of ratios.

\section{GREEK ORIGINS OF SIMILARITIES BETWEEN MATHEMATICS AND MUSIC}

Although the works of arithmetic and music compiled by Boethius (Friedlein, 1867) provide relevant material for the understanding of ratio on treatises of theoretical arithmetic and music in the late Middle Ages, it is crucial to turn to Greek Antiquity.

Questions concerning the role of Greek music in the development of pure mathematics were already raised in the beginning of the 20th century by p. Tannery (Tannery, 1915). Szabo also posed similar questions in his attempt to show that pre-Eudoxian theory of proportions developed initially as an inheritance from Pythagorean theory of music. His conjecture is strongly based on an astute analysis of the Greek technical terms involved in both theories, such as diastema, oroi, analogon and logos and their employment in an experiment mentioned by Gaudentius in which Pythagoras stretched a string across a ruler-the so-called canon or monochord — which divided this instrument in twelve parts (Szabo, 1978).

Pythagoras' discovery, by means of the monochord experiment, that ratios of small integers underlie the basic consonant musical intervals casts light on a large number of discussions about musical theory that have ratios as their main characteristic, both in Greece as well as after Hellenistic times. These discussions came mostly from the establishment of the link between music and mathematics, reasonably developed and with adequate theoretical power to ground and/or to corroborate the principles of the Pythagorean school. The reflection of such discussions in the treatment of ratios and proportions both in theoretical music as in mathematics in the late Middle Ages and the Renaissance, with regard to terminological, structural similarities and in the discourse as well as to theories in a broader sense, is a subject deserving closer attention.

In the aforementioned experiment, Pythagoras would have at first plucked the whole string and consecutively half, three fourths and two thirds of it, obtaining respectively music intervals of octave, fourth and fifth - the three most important consonances in ancient Greek music-pro- 
duced thus by ratios 12:6, 12:9 and 12:8. Questions concerning the credibility of such a story in Pythagorean context, as well as the existence of the monochord at this time and even whether the simple aforementioned ratios underlying musical consonances were actually uncovered through such an apparatus will be not considered in the present article. I am more concerned now with historical and epistemological consequences of the establishment of the relationship between simple ratios and musical consonances_-and more generally ratios of whole numbers and pure musical intervals - in the cultural context mentioned above.

In the Pythagorean school, musical interval is provided by ratios consisting only of whole numbers. It does not mean that it was impossible to divide the string continuously but that only the divisions providing ratios of whole numbers - in today's terminology—would be capable of producing a musical interval. Aristoxenus, by contrast, describes scales with half tones, fourth tones etc., as well as an integer tone occupying 12 equal parts-notions which find no epistemological resonance with the mathematics of his time but which betray signs of the idea of logarithm and also provide basic support for a mathematical understanding of 'equal temperament'. He conceived the gamut of pitch as a continuous line which could be divided into simple fractions, so that the octave could be divided into six tones, the tone into semitones or quarter-tones, the 4th into two tones and a semitone, and so on (Schechter, 1980).

In preferring geometry to arithmetic in solving problems that involve relations between musical pitches, Aristoxenus maintained the possibility of dividing the tone in two equal parts, provoking a large number of reactions expressed for instance in Sectio Canonis and much later in the De institutione musica of Boethius, which gave birth to a strong tradition in the Middle Ages. Conceiving the theoretical nature of music as essentially geometric, Aristoxenus understood pitches, musical intervals and also distance as unidimensional magnitudes - continuous quantities - that should follow the rules of the Euclidean geometry and should be capable of being divided continuously, which inevitably raises questions concerning the nature of ratio in this context.

The term ratio- $\operatorname{logos}$ - has a very broad semantic field in Ancient Greece. We find this term for the first time in a fragment of Heraclitus (6th-5th century BC), who complained that most men failed to comprehend the logos, the universal principle through which all things are interrelated and all natural events occur. According to Heraclitus, logos not only designates things, but is the only unifying resource for the arrangement of things in the world. Logos is the general plan according to which everything happens and also the model for the concordance and balance between the distinct and contrasting forces in universe (Ierodiakonou, 1999). In Hippocrates (5th century BC), logos in mathematical context is a concept that measures the relation between two geometrical commensurable magnitudes. With the enlargement of the conception 
of ratio by Eudoxus (4th century BC), Euclid defined logos in his Book V of The Elements as relation between two magnitudes of the same type including incommensurable magnitudes, an important step to the understanding of ratio as a continuous magnitude in musical context by Aristoxenus. An important concept strongly linked to logos is proportion-analogia —which first served as a tool for solving problems but soon acquired a more general theoretical status systematized by Euclid in book V of The Elements. Plato and Aristotle knew a significant part of the doctrine of analogia and their interest lay in the fact that analogia represented a medium by which one could conceive of an identical form in distinct contexts (Crubellier, 1996).

Also in the light of such considerations, a comparison with the way in which Euclid manages ratio, proportion, number and magnitude demonstrates that these concepts have different natures as mathematical categories for the Greek mathematician and also brings to light vestiges of links between ratio and musical interval and in a broaden sense between mathematics and music in the structure of Euclid's thought. As I will show latter, there are further elements of structural and terminological nature in the underlying discourse as well that disclose parallels between mathematical and musical thinking at that time in the treatment of ratio and proportion.

From such similarities we can infer that, from later times and particularly in Book V of Euclid's Elements, ratio—-logos—was originally seen as a generalization of musical interval—and theory of ratio as a generalization of theory of music — whose nature was clearly distinct from number, magnitude and proportion, the latter in particular the tool by which ratios concerning different contexts — in the case, mathematics and music — are linked. In this context, ratios were entities very different from numbers, although they are capable of being manipulated by means of structurally similar operators, evidenced for instance in the categorical difference between equality of numbers and proportionality between ratios.

In the period between Antiquity and the late Middle Ages, there occurs a significant change in the use of ratio, in which conceptions of operations strongly tied to contiguous musical intervals are eventually replaced by theories that admit the composition of general ratios with an essentially arithmetic character, for example, the idea that a ratio is equal to a number. The transformation of the concept of ratio from something closely tied to logos in the classic Greek Period with a broad, but definitely not arithmetical, meaning expressing a relationship between numbers or homogeneous magnitudes - in this case, lengths and musical intervals - to an arithmetical one not before 1st century AD with Heron (Fowler, 1989) and stronger in the late Middle Ages is quite significant for the understanding of the contributions of theoretical music in the emergence of an arithmetical theory of ratio, which includes among other things not only the identification between ratio and number but also between proportion and equality. Such a 
"chain of change" defines different theories of ratio (Sylla, 1984) some times with geometrical nature, other times with arithmetical and even with musical traces related to the similarities between math and music that I have already described and discuss more fully below.

\section{COMPOUNDING RATIOS}

Some indicators of the different theories attached to the concept of ratio are found in connection with issues such as Euclid's restriction on the operation of composition with ratios - sugkeimenon-implied in definitions 9 and 10, Book V (Heath, 1956, p. 132) as well as in proposition 23, Book VI (Heath, 1956, p. 181). Such operations consisted of compounding ratios of the type $a: b$ with $b: c$ to produce $a: c$, called ratio duplicata double the original one, which then allows the repetition of this process with $c: d$, resulting in the ratio triplicata $a: d$ and so on, that is:

$$
(a: b) .(b: c)(c: d) \ldots
$$

Mathematically speaking, there is no reason to define this operation in such a way and we would never so define it if we did not first observe its significance from a musical viewpoint, which understands what is otherwise a purely mathematical phenomenon as the adjoining of contiguous intervals. This operation, which has strong musical affinities, required that the second term of a ratio should equal the first term of the next ratio. This means that if one wishes to compound for instance $(3: 4)$ with $(3: 4)$, it is necessary at first to adapt both ratios so that the second term of the first coincide with the first term of the second. In the case, the first is proportional to (9:12) and the second is proportional to (12:16). And then, by the definition ex aequali 17 of book V of The Elements, which says:

Def. 5.17. A ratio ex aequali arises when, there being several magnitudes and another set equal to them in multitude which taken two and two are in the same proportion, as the first is to the last among the first magnitudes, so is the first to the last among the second magnitudes. (Heath,1956, p. 115)

$$
\begin{aligned}
& (3: 4) .(3: 4): \because(9: 12) \cdot(12: 16): \because(9: 16) . \text { Mutatis mutandi } \\
& (8: 9)(3: 4)(3: 4): \because(8: 9)(9: 12)(12: 16): \because(8: 16): \because(1: 2) .
\end{aligned}
$$

As mentioned above, such an operation has a powerful structural resemblance with the composition of contiguous musical intervals, as the following figure representing the string of the monochord illustrates. 


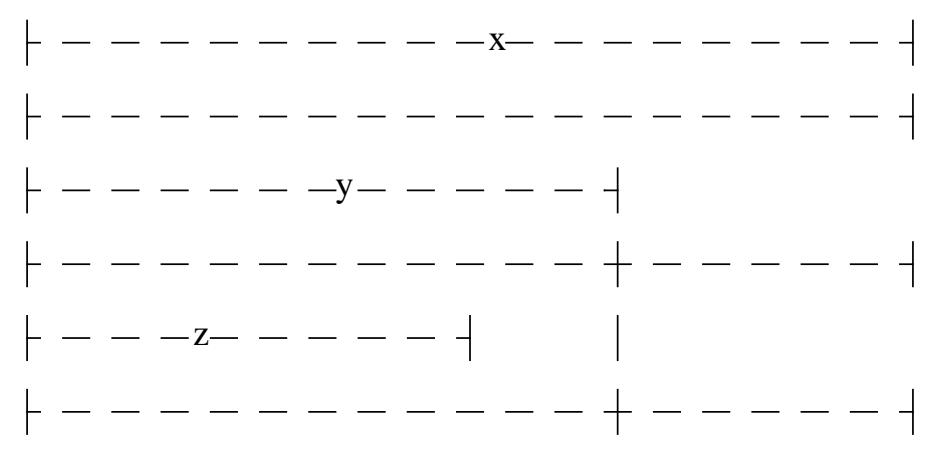

In this case, $z: x::(z: y)(y: x)$ or musically, the interval produced by the ratio $(z: x)$ is the composition of the contiguous intervals $(z: y)$ and $(y: x)$. For instance, $(2: 3) .(3: 4)::(1: 2)$ is structurally equivalent to the musical combination of the interval of a fifth with that of a fourth in order to generate a octave. Precisely this example is mentioned in a fragment attributed to Philolaus by Diels/Kranz (Diels, H.; Kranz, W.; 1996, p. 409, 44, B 6.10ff), whose translation is:

"The octave comprises a fourth and a fifth. The fifth is a whole tone bigger than the fourth. Then there is a fourth from the 'hypate' to the 'mese' and there is a fifth from the 'mese' to the 'nete'. There is a fourth from the 'nete' to the 'trite' and there is a fifth from the 'trite' to the 'hypate'."

Thus, compounding must not be confused with multiplication although the former presents strong structural similarities with the latter. Now, Pythagoras' Experiment seems to inform us of two things. The first and more general point it makes is that mathematical ratios underlie musical intervals. But it also tells us more specifically that the compounding ratios underlie the composition of musical intervals, and even that, due to such a link, composition of ratios in a Euclidean fashion is handled in this way.

This practice reveals important structural resemblances with music in mathematical discourse. Together with terminologically similar features stemming from the same period, such practice also defines a tradition in the treatment of ratio and proportion in mathematics that is in evidence, alongside other quite different traditions, up to 17th century (Sylla, 1984), with varying degrees of emphasis in different epochs and/or fields, as I will describe later. During the 17th century, this first tradition is gradually abandoned and a slow transformation occurs in which ratios in propositions concerning proportions $(A: B:: C: D)$ are treated more and more as equations between quotients $(A \div B=C \div D$ ) (Grosholz, 1987). In this second tradition, a ratio is not 'as' another but is literally 'equal' to another ratio. 
By contributing to the comprehension of apparently distinct — but structurally similar - meanings attributed to the aforementioned operations with ratios, the new understanding that results makes possible for instance the mathematical systematization of diatonic scales tuning, based on cycles of fifths and octaves, i.e., in the composition of the corresponding ratio in accordance with Euclid's procedure (Heath, 1956, p. 132) —and structurally equivalent to multiplication with constraints-, of the fractions $1: 2$ and $2: 3$, respectively, a process which is also representative of the discussions mentioned initially.

\section{DisCOURSE AND TERMINOLOGY}

Apart from the compound ratios operation mentioned above, the similarities between mathematics and music come to light for instance when Euclid discusses the equality of numbers and magnitudes and 'never' refers to ratios as being equal, but says that they are 'in the same ratio' or that one ratio 'is as' another one (Grattan-Guinness, 1996) in a proposition concerning proportions.

The structural resemblance and ontological difference between compounding and multiplication, the idea of equality of ratios in Euclid is probably not as natural as that of numbers or magnitudes. Such a way of establishing relations between ratios gains greater meaning when we consider that, for instance, $d o-s o l$ and $l a-m i$ are the same intervals —in this case, a fifth — but they are not equal, inasmuch as the latter is a sixth above the former, or even that do-sol 'is as' la-mi. Then, proportion — analogia — and equality are different and must not be confused. Here a significant question arises concerning Euclid's avoidance of speaking of ratios as 'equal' ratios.

With regard to terminology, Euclid uses duplicata and triplicata in definitions 9 and 10 respectively of Book V of The Elements to express in the first case the square and in the second the cube, as presented below:

Def. 5.9. When three magnitudes are proportional, the first is said to have to the third the duplicate ratio of that which it has to the second.

Def. 5.10. When four magnitudes are continuously proportional, the first is said to have to the fourth the triplicate ratio of that which it has to the second, and so on continually, whatever be the proportion. (Heath, 1956, p. 114)

He generalizes such an idea in definition 17 (mentioned above). 
This terminology reveals similarities with the idea of compounding musical intervals, since the increase in musical pitch occurs in logarithmical fashion, in this case, the duplicate/triplicate of a musical interval corresponds to raising the corresponding ratio to the 2 nd and 3 rd powers respectively. Thus, the compounding of a ratio $(a: b)$ with $(b: c)$ to produce a ratio duplicata $(a: c)$ is structurally similar to that of compounding the intervals, for instance, do\#- $f a \#$ with fa\#- $s i$ to produce $d o \#-s i$, thus creating a duplicate interval. The correspondence proceeds in an analogical way for the triplicata and proportion ex aequale, if we repeat the process three times and $n$ times respectively.

The resemblances presented above corroborate that, for cultural reasons (Barker, 1989; GrattanGuinness, 1996), Euclid, along with his contemporaries and predecessors, probably conceived of the theory of ratio as a generalization of music inasmuch as the proprieties of the strings and comparisons between pitches, as well as calculations related to such magnitudes through ratio and proportion, were a relevant part of mathematics from the Pythagoreans until Euclid (McClain, 1986).

This argument is strengthened by the lack of evidence of handling and operating ratios of magnitudes before the development of Eudoxus' theory of proportions in Book V of The Elements. It is probable that at this period the treatment of ratios occurred only through the well-developed anthyphairetic theory (Fowler, 1987). This procedure allows the evaluation of ratios through successive subtractions between their terms, which in turn probably allowed for the systematization of the concept of proportion - in term of part and parts - involving numbers-not applicable to incommensurable quantities_-in definition 20 of Book VII of The Elements:

Def 7.20. Numbers are proportional when the first is the same multiple, or the same part, or the same parts, of the second that the third is of the fourth. (Heath, 1956, p. 278)

At this point, it is worth commenting on an important interpretation that not only elucidates the non-arithmetical nature of ratio in Classic and Hellenistic periods, but also contributes to its comprehension in the context of the similarities between music and mathematics. Such an interpretation was presented by Fowler (Fowler, 1981) related to a previous one presented by Riddell (Riddell, 1979) in light of which definition 5 of Book V of The Elements for proportion including incommensurables can be read as: "two ratios are proportional if they provide or underlie the same standard — in this case, geometrical—established by the occurrence of two periodical phenomena". Definition 5 of Book V says that: 
Magnitudes are said to be in the same ratio, the first to the second and the third to the fourth, when, if any equimultiples whatever be taken of the first and-third, and any equimultiples whatever of the second and fourth, the former equimultiples alike exceed, are alike equal to, or alike fall short of, the latter equimultiples respectively taken in corresponding order (Heath, 1956, p. 114).

Such a definition is equivalent to say that $A: B: \because C: D$ if and only if:

$$
\begin{gathered}
M A>N B \Rightarrow M C>N D \\
M A=N B \Rightarrow M C=N D \\
M A<N B \Rightarrow M C<N D
\end{gathered}
$$

Supposing the magnitudes in question to be lengths, the aforementioned set of formulas are in turn equivalent to, say, $A: B: \because C: D$ if and only if the following two configurations present the same pattern apart from scale.
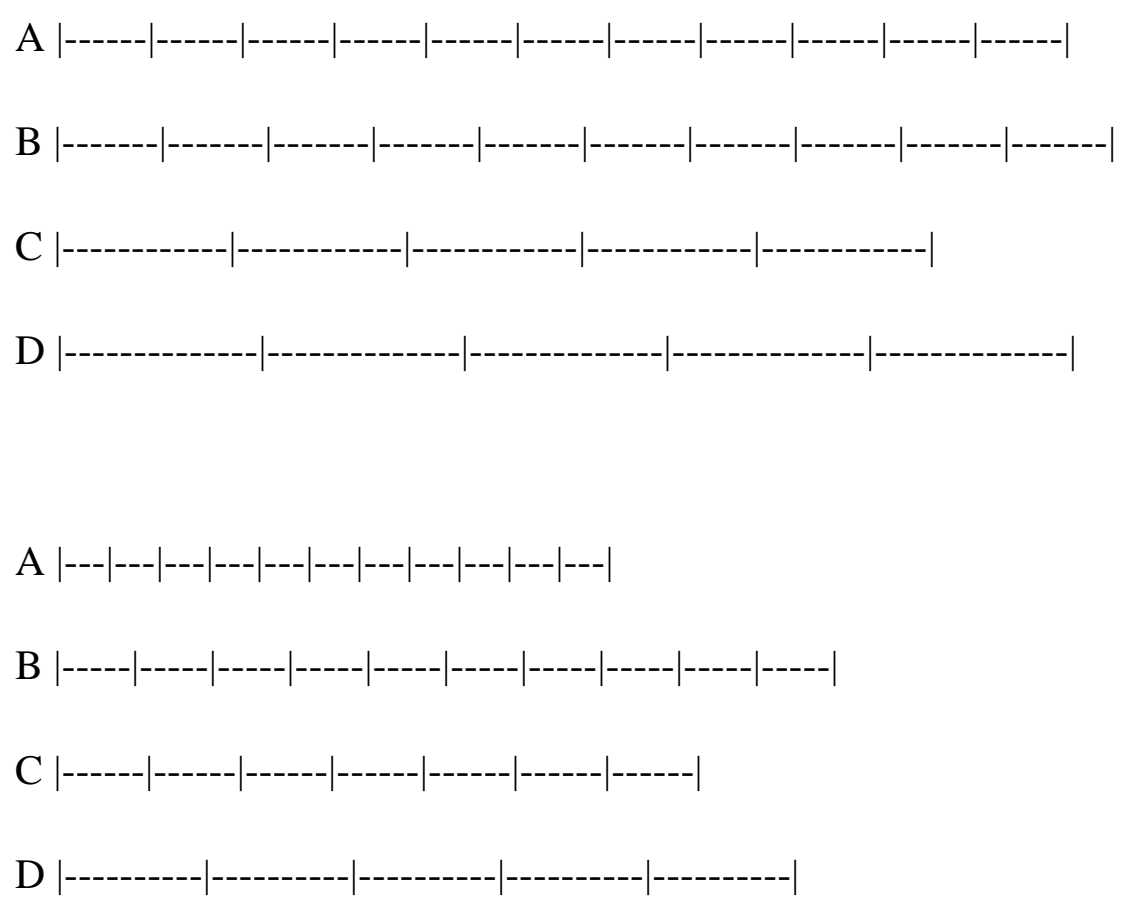

Thus, in the light of this interpretation, ratios are proportional if and only if the same pattern underlies them.

If we then consider as well that the interpretation of Fowler can also be related to anthyphairetic theory (Fowler, 1981, p. 70), we now are in a position to appreciate ratio in the Greek sense as an idea associated with the underlying abstract standards that, by means of proportions, or anal- 
ogies, make possible a link between contexts that are otherwise quite different and distinct. This means that ratio would be a common link between diverse contexts that agree with the understanding of proportion - analogia - by Plato and Aristotle, as I have discussed above.

In this way, over the course of many interpretations and theoretical constructions from Antiquity to the early modern period, ratio has served as a tool of comparison and particularly, a common thread between diverse contexts, an invariant with respect to proportion, that is, as something that remains the same while other things change around it. In the case in point, when one varies comparison of lengths and musical intervals in their corresponding areas, the common aspects between such concepts and the way to establish the link between both contexts will be systematized by ratios and proportions, respectively.

The similarities remarked above allow us to categorize mathematical ratios at first as a generalization of musical intervals, capable of being operated, thanks to their musical heritage, by means of composition according to the method described before. They also raise questions concerning the mathematical theories underlying the manipulation of ratios from Antiquity until the late Middle Ages and Renaissance, especially in musical contexts.

This new perspective may also help us in gaining a better understanding of the categorical distinction between ratio and proportion, which does not seem to have been well understood in the Middle Ages: while in Antiquity ratio was clearly viewed as a definition involving two magnitudes of the same kind whereas proportion functioned in all the aforementioned situations either as a logical proposition to which one may attribute a valuation or as a tool to make a proposition true through the link between two situations capable of being expressed by ratios, in the Middle Ages there reigned, on the subject of the status of these two concepts, nothing but confusion.

\section{LATE ANTIQUITY: FIRST SIGNS OF ARITHMETIZATION OF THEORIES OF RATIO}

The beginning of the detachment of the concept of ratio from music seems to have originated in the transversal theorem of Menelaus, or with Theon (Grosholz, 1987). The features of this detachment were transmitted in the Middle Ages by Jordanus Nemorarius, Campanus and Roger Bacon (Sylla, 1984). For instance, we can find evidence of new theories for ratios in Pappus' definition of a curve which involved compound ratios in a general sense. Without the constraint imposed by Euclid, such a definition reveals significant modifications and evolution of the concept of ratio. It is worth commenting that at this time, Euclid's The Elements underwent changes which may signify a partially arithmetization of ratios. In the hands of Theon of Alexandria (4th 
century AD), for instance, Euclid's The Elements underwent slight emendations, in particular, with the interpolation of definition 5 of book VI which distorts the true Euclidean sense of compounding. It says:

Def. 6.5. A ratio is said to be compounded of ratios when the sizes $(\pi \eta \lambda \iota \kappa o \tau \eta \tau \varepsilon \sigma)$ of the ratios multiplied together make some (?ratio, or size). (Heath, 1956, p. 189)

It is remarkable to note that Theon's version supplied the text for Greek editions of Euclid until the 19th century, a fact which inevitably contributed to re-interpretations concerning the nature of ratio and proportion also in musical contexts.

Pappus (4th century AD) generalizes the definition of conic sections and other curves given by Apollonius (Heath, 1931, p. 453-454), and offers the following proposition, known as the Problem of Pappus: given an even number of lines $r i, i: 1,2,3, \ldots, 2 n$, construct lines containing the point $P$, in such a way that each of these lines intercepts any of the original lines in points $C i$ belonging to $r i$ and satisfying the following relation involving compound ratios:

$$
(P C 1: P C 2) .(P C 3: P C 4) .(P C 5: P C 6) \ldots(P C 2 n-1: P C 2 n)=c o n s t
$$

In this problem, there is no requirement that the second term of a ratio must occur again in the first term of the following ratio, as in Euclid, and thus the operation with ratios begins to look similar to multiplication, in a manner that is not merely structural. Pappus extended the technique of operation with ratios, since Apollonius defined conic sections and other curves through similar procedures using only four and six lines, respectively (Heath, 1931, p. 453). Such a procedure was capable of being treated geometrically, by specifying that the ratio of the product of two or three segments is constant and by seeing such products as the area of a rectangle and the volume of a cuboid, respectively. Pappus justified this requirement of extending the definition of composition of ratios by stating the impossibility of a geometrical interpretation in a fashion analogous to Apollonius' procedure with a greater number of lines, which means that such a change results from an inductive and practical procedure inside mathematics.

By generalizing the relationship between the components involved in operations with ratios, the Greek mathematicians extended the spectrum of Greek geometrical techniques, and thus approximated semantically - and not merely in similarity of structure - the operation of arithmetical multiplication, as well as that of converting ratios into rational numbers. Such changes replace lines with numbers that make possible their multiplication and division. A similar transition in the use of ratios - one that is closely related to the focus of this exposition - was to develop later, in medieval European (Grattan-Guinness, 1997, p. 84). In spite of this, it is worth 
emphasizing that the changes in the ratio's nature-and the correspondent underlying theories-from the Greek logos to the idea of rational number did not occur regularly in either time or space.

At this point, one can identify at least two traditions in the Greek treatment of ratios/proportions that persisted up to the late Middle Ages and the Renaissance and were evident even in 17th century. One of these traditions, which was associated with theoretical mathematics, music, and physics, goes back as early as Euclid. This is the tradition which appears, for instance in Bradwardine's De proportionibus velocitatum in motibus, in Nicole Oresme's De proportionibus proportionum, as well as in the first edition of Newton's Principia, and which admits, among other things, operations with ratios subject to the constraints imposed by Euclid. The second tradition is related to practical calculations, and appeared almost always in the Middle Ages in close or remote connection with astronomy (Sylla, 1984). It is reasonable to think that both geometrical and arithmetical tendencies were often present in medieval mathematical texts concerning ratios and sometimes simultaneously and 'strangely mingled' in the same text, be it in the context of compounding and multiplying ratios (Syllla, 1984), or in the definition of ratio by the medieval theorists (Drake, 1973). Actually, the theories presented above represent the two poles of the ways in which ratios, the definitions and the operations on ratios could be treated.

It is thus relevant to ask in which way each of the similarities mentioned above and also other possible ones were inherited by the theories underlying ratios and proportions establishing an authentic Diaspora. I will try to bring out, on the one hand, how such similarities proliferated in late Middle Ages and Renaissance in mathematics and music reaching scholars such as Bradwardine, Oresme, Le Fevre d'Etaples, Ciruelo, Salinas etc. and also, on the other hand, how the practical needs of theoretical music polarized the theories of ratio and proportion in the direction of geometry and consequently how such needs contributed indirectly to the emergence of arithmetical — in today's terminology — theories of ratio, which gradually identified ratio with number, proportion with equality and also transformed 'compounding' into multiplication. That means a gradual abandonment of the conception of number as whole numbers in musical contexts in favor of a conception of number as continuous in nature, a change that has parallels also in the methods of division of the monochord in 15 th century. 


\section{EARLY MiDDLE AGES}

Boethius is a case in point. His thought is organized according to the idea that all things were established harmonically in dependence on number-integer in today's terminology - in other words, that the science of number rules the world. His works De institutione musica and De institutione arithmetica was explored by many theoretical musicians from Carolingian times until 16th century. Although he does not do so explicitly, Boethius nevertheless seems to treat ratios in the classical Greek manner, using expressions and terms like componere, coniungere, adglomere, procreare, creare, exorior etc. to express the idea of assembling as well as differentia to express the operation which is the opposite of compounding. For example, Boethius compounds a sesquialter with a double to obtain a triple ratio, i.e., a fifth compounded with an octave, which generates a compounded fifth.

Accordingly, the 'difference' between sesquialter and a sesquitertia is an epogdous, i.e., the fifth minus a fourth is a tone. According to Boethius, Ex duplici igitur et sesquialtero triplex ratio proportionis exoritur (Friedlein, De institutione arithmetica libri duo, II, 3, 1867, p. 85) and Unde notum est, quod inter diatessaron et diapente consonantiarum tonus differentia est, sicut inter sesquitertiam et sesqualteram proportionem sola est epogdous differentia (Friedlein, De institutione arithmetica libri duo, II, 54, 1867, p. 172).

It is worth commenting that Boethius adopted the latin translation proportio and proportionalitas, for logos and analogia, respectively, that influenced tremendously either directly or indirectly the choice of terminology for such concepts throughout the Middle Ages, even among translators who worked with Arabic texts or consulted directly Greek works. For instance, through the version of Adelard, the Boethian terminology for ratio predominated during the High Middle Ages, as some later editions of The Elements illustrate. Contributing to the medieval misinterpretation of ratio and proportion, such terminology was superseded only with Zamberti's translation of The Elements (Venice, 1505) directly from Greek, which triggered the gradual re-establishment of the previous terminology for ratio and proportion. 


\section{RATiOs IN THE LATE MidDle AGES}

Up to the 14th century and slightly less intensely towards the end of this period, compounding was predominantly performed in the classical Greek style. Thus to deal with the ratio compounded of $a: b$ and $c: d$ one needed to find a magnitude $e$ such that $c: d:: b: e$. Then the compound ratio would be $a: e$. Gradually, however, the more explicit notion of multiplication of ratios was introduced.

As rational numbers acquired greater relevance and operations with ratios acquired arithmetical meaning, the changes in the theories underlying ratio and proportion brought in parallel the growth of the interaction between arithmetic and both algebra and geometry which required an arithmetic theory for ratios. Such crises gained a more systematic character with Nicole Oresme in his De proportionibus proportionum, written in the 1300's, which translates Euclid's commensurable and incommensurable geometric magnitudes as rational and irrational ratios, conceiving of them as numbers. We could say reciprocally that irrational numbers-or ancient incommensurable magnitudes-were arising in musical contexts, when previously the sound produced by such ratios was not considered music. Proposing a more comprehensive view concerning proportionality, Oresme applied this interpretation of ratio in different areas of mechanics and entrenched further the proposal that any number could be represented by a length.

Nevertheless, it is important to stress that, despite the aforementioned changes, Euclid's theories of ratio were still popular in the late Middle Ages and influential enough to ensure that indefiniteness between the two theories persisted even up to the time of a work like the first edition of the Principia of Newton in 1687 (Sylla, 1984), where the Euclidean theory of ratio is mixed with a new arithmetical version systematized by Oresme (Grattan-Guinness, 1997, p. 162).

In the late Middle Ages and particularly in the 14th century, the character of the theories of ratios underwent important changes. It is essential to note that Campanus' Latin translation of Euclid in 13th century is generally considered the main source for the 14th century ratio theory of Bradwardine and Oresme and the authoritative medieval text of The Elements until the 16th century, when it was replaced by translations made directly from the Greek. Together with other 14th century sources, Campanus' translation had an arithmetical terminology that was not derived from the geometrical ratio theory of Book $\mathrm{V}$ of Euclid, but instead from a number of different sources including very likely the Arithmetic of Jordanus de Nemore from 13th century.

In most part of the allusions to book V of The Elements in the 14th century, whose Greek version contains a theory of ratios in respect of magnitudes, the version of the aforementioned definition for the proportionality of ratios is not the Eudoxian and geometrical definition 5 of Book V- 
for instance, in the Bradwardine's Tractatus de proportionibus - , but instead one in terms of the 'denominations' of ratios presented in the Campanus' version mentioned above. The meaning of the term denominatio in this context is quite arguably fluctuating mainly between a ratio as a fraction reduced to its lowest terms or the quotient of that fraction. Such a resource for defining ratio is equivalent to treating ratios as if they were fractions, which has important terminological implications in particularly concerning ratios between incommensurable magnitudes — or arithmetically speaking, irrational ratios—which become at first inexpressible. One possible solution would be to consider rational approximations and/or to accept decimal fractional as pertaining to the category of numbers, which apparently did not happen before 16 th century. Independently of the solution for this problem, such terminology represents a concrete ontological point of contact between numbers and ratios attributing eventually to both concepts continuous character. The arithmetical theory of ratio manifested in Campanus' version of Euclid's Elements equipped with the medieval arithmetical ratio terminology of 'denomination' provided the foundation for the late-medieval understanding of ratios in mathematical contexts.

Musical theory of ratio could also have contributed to the indefinite nature of mathematical ratio during this period. Examining Boethian influence on the quadrivium, Peden conjectures an influx of such theory in medieval mathematical texts eventually as a result of the utilization of such a theory as a support to arithmetical exercises for students (Peden, 1994). This musical influence on a wider theory of ratio could have strengthened the re-establishment-now, differently from Szabo's conjecture mentioned above_of a musical character in some medieval mathematical texts involving ratios, rescuing and reintroducing Platonic-Pythagorean ideas into mathematics, which also contributed to the coexistence of different and/or mingled traditions concerning medieval treatment of ratios.

On the other hand, Campanus' translation together with the aforementioned sources are also representative of the important contribution of this period to the arithmetization of the theories of ratios. Interestingly, such a stream has an important repercussion in the theoretical Renaissance music insofar as Campanus' translation was the source for theoreticians of this period like Erasmus Horicius, who is the first in the Renaissance to apply explicitly Euclidean geometry to solve problems in music theory (Palisca, 1995). Such a situation brings together on a reasonable theoretical level the seed of a continuous nature of ratio in musical contexts which will eventually provide the concept which musical theoreticians of the 16th century will use to deal with problems involving ratio in music. Besides the Euclidean structure very characteristic of his Musica, Erasmus used the Latin terminology of Campanus (Palisca, 1994, p. 158), which inevitably grants an arithmetical nature to ratio, bringing it structurally closer to number, as had never been the case in musical theoretical context. 
But previously, it is worth commenting on some remarkable aspects of the treatment of ratio, particularly in Bradwardine and Oresme, who, as already noted, used Campanus' translation. In his discussion of ratios in his De proportionibus velocitatum in motibus, Bradwardine (Crosby, 1955) says: "Si fuerit proportio maioris inaequalitatis primi ad secundum ut secundi ad tertium, erit proportio primi ad tertium praecise dupla ad proportionem primi as secundum et secundi as tertium."

This quotation is precisely definition 9 Book $\mathrm{V}$ of The Elements which characterizes the vestige of a musical terminological similarity by means of the latin term dupla, thereby evincing the mingled traditions concerning medieval treatment of ratios. Further evidence of the continuing popularity of Euclid in the treatment of ratios particularly with regard to the aforementioned musical resemblances surfaces in Oresme's treatment of compound ratios as the result of a continuous series of terms.

In the second half of the 14th century, Oresme undertook a very detailed study of ratios in his Algorismus proportionum and his De proportionibus proportionum, the latter written a few years later. It is worth noting the influence of the terminological similarities mentioned above on the Algorismus proportionum — dedicated to the musician Philippe de Vitry-which is the first known systematic attempt to present rules of operation for multiplication of ratios involving integer and fractional exponents (Curtze, 1868). And it is also relevant to note that he used the expressions additio and differentia to express what we call today multiplication and division of ratios respectively.

In addition to performing compounding in the traditional manner, Oresme noted explicitly that one could compound ratios by multiplying the antecedents and then multiplying the consequents (Katz, 1993, p. 292), namely, that the compounding of $a: b$ and $c: d$ was directly $a b: c d$. Possibly, the continuing way to achieve such a result was that $a: b$ and $c: d$ should be expressed as $a b: c d$ and $a c: a d$, respectively according to proposition 18, book VII of The Elements. Interestingly, an important step towards the arithmetization of the theories of ratios, which represents also a more explicit change concerning the nature of such a concept, is Oresme's attempt to deal with what we would call irrational exponents. The French mathematician presented not only denominations of rational ratios using numbers and fractions-what already constituted an useful element to the arithmetization—but also indirectly conjectured irrational ratios, inexpressible with the previous nomenclature. Asserting that fractions of ratios are insufficient to exhaust all the real numbers in modern language, he actually conceived of ratio yet without rigor as an authentic continuum. According to Oresme, 'every ratio is just like a continuous quantity with respect to division', that is, that one could take any possible 'part' of such a ratio. 
He employs 'part' and 'parts' to refer to ratios with fractional exponents in relation to the corresponding unitary one. This is precisely the terminology used by Euclid ( $\mu \varepsilon \rho \circ \varsigma$ and $\mu \varepsilon \rho \eta)$ in definition 20 book VII of The Elements in an arithmetical context expanded to a logarithmic one. This is a mathematical technique which did not exist in Aristoxenus' time yet is crucial for the comprehension of the musical temperament as it may have been conceived by him.

The Algorismus proportionum provides the essential tools necessary for comprehending temperaments involving proportional means in a mathematical fashion, in a period in which we begin to find other temperaments besides the Pythagorean and even what we could call a proposal of equal temperament, which appears as one of the five treatises on music theory, found in an anonymous fourteenth-century manuscript, dated in Paris, 12 January 1375 (Ellsworth, 1974, p. 445).

The terminological and structural similarities in mathematics and music set forth above, particularly those found in contexts involving ratios and proportions, lead one to wonder about the musical repercussions of the systematization of such operations with ratios that was established by Oresme, who was himself in contact with Philippe de Vitry. In the same vein, one would like to know more about the role that Oresme's treatises, Algorismus proportionum and De proportionibus proportionum, played in the achievements of Vitry or Johannes de Muris, who had elucidated the whole musical theory of his period in a strictly mathematical style (Werner, 1956, p. 131). Although it is not a simple matter, some considerations concerning the idea of mensuration from 13th to 14th century may provide some initial insights.

Theorists of the thirteenth century conceptualized durations as attributes of sound, which are not capable of being compared mathematically, that is, rhythmic hierarchy was based on planes of duration, which constituted totally independent mathematical categories with respect to their 'greatness' in modern language.

The beginning of the 14th century witnessed significant changes in the ontological status of ratio in musical contexts, be it in the context of rhythm or in that of pitch. The position of the theorists of the thirteenth century changes significantly with Johannes de Muris, who presented a new understanding of the notion of a rhythmic part, and a new conception of whole-part relationship in music (Tanay, 1993, p. 36). Not content with repeating the traditional numerical theory, Johannes applied his mathematical skills to the observations of contemporary musical practices. His Notitia ars musicae (1319 or 1321) reconsidered the controversial question of the duple versus triple division of notes values, defending the view that 'time belongs to the genus of continuous things, therefore may be divided in any number of equal parts' (Palisca, 1995, p. 750). 
Concerning the changes in the nature of ratio in pitch contexts, such a period saw the appearance of the Lucidarium in arte musicae planae (1317/1318) of Marchetto of Padua. The Paduan theorist sowed the seed for the arithmetization of ratios in theoretical music without geometrical resources by being the first to propose division of the whole tone into five equal parts (Herlinger, 1981, p. 193) — a mathematical systematization which lead eventually to a substantial change in the conception in the light of which ratios were treated by theorists in music, and consequently to the arithmetization of theory of ratios in theoretical music.

Although the particular progress of such arithmetization in music contexts in this period must remain an open question, we may conjecture that Nicole Oresme brought to a conclusion the mathematical thought of an entire generation (Lowinsky, E.E., 1954, p. 543), by creating important notation and techniques which contributed immensely to the development of rhythmic and polyrhythmic structures in Western music. Nevertheless, the influence of Oresme's special treatment of ratios of ratios in mathematics is surprisingly limited (Grant, 1966, p. 69) and does not seem to exist significantly before the beginning of the 16th century at the University of Paris with scholars like George Lokert and the Portuguese Álvaro Thomas, the latter of whom seems to be the only author who shows an extensive acquaintance with, and understanding of, Oresme's treatise (Grant, 1966, p. 71).

Similarly to logos in Ancient Greece, ratio participates in a vast field even in medieval musical contexts outside of rhythm and pitch, a fact that makes more difficult the task of delineating more precisely the historical path of its development and/or of establishing how theorists dealt with such a concept in a general sense. An interesting example of this comes to light in 15th century in the isorythmic constraint initially present in the music of Ars Nova which determines a rhythmic pattern in the course of the musical composition. The musical form was generated by means of a rhythmical pattern which was sustained throughout the piece. The procedure of maintaining throughout the piece a mensuration that had been established for a certain section can be seen in the beginning of a motet by John Dunstable (figure 1) presented by Bukofzer (Bukofzer, 1942, p. 179).

Although medieval theorists simply described the isorhythmic device without a hint as to its intellectual foundations, it is quite likely that an abstract idea in which proportion-analogiabetween ratios played a major role underlay in its creation. In accordance with the Pythagorean conviction that numbers form the essence of all things instead of being an outcome of esthetic experience, ideas of numerical ratio and of proportion inform the piece in that they provide important links in the rhythmical structure. Whereas numerical ratios manifest themselves in whole numbers expressing the time-values of the different notes, proportions maintain rhythmic schemes in the various parts of a composition. 

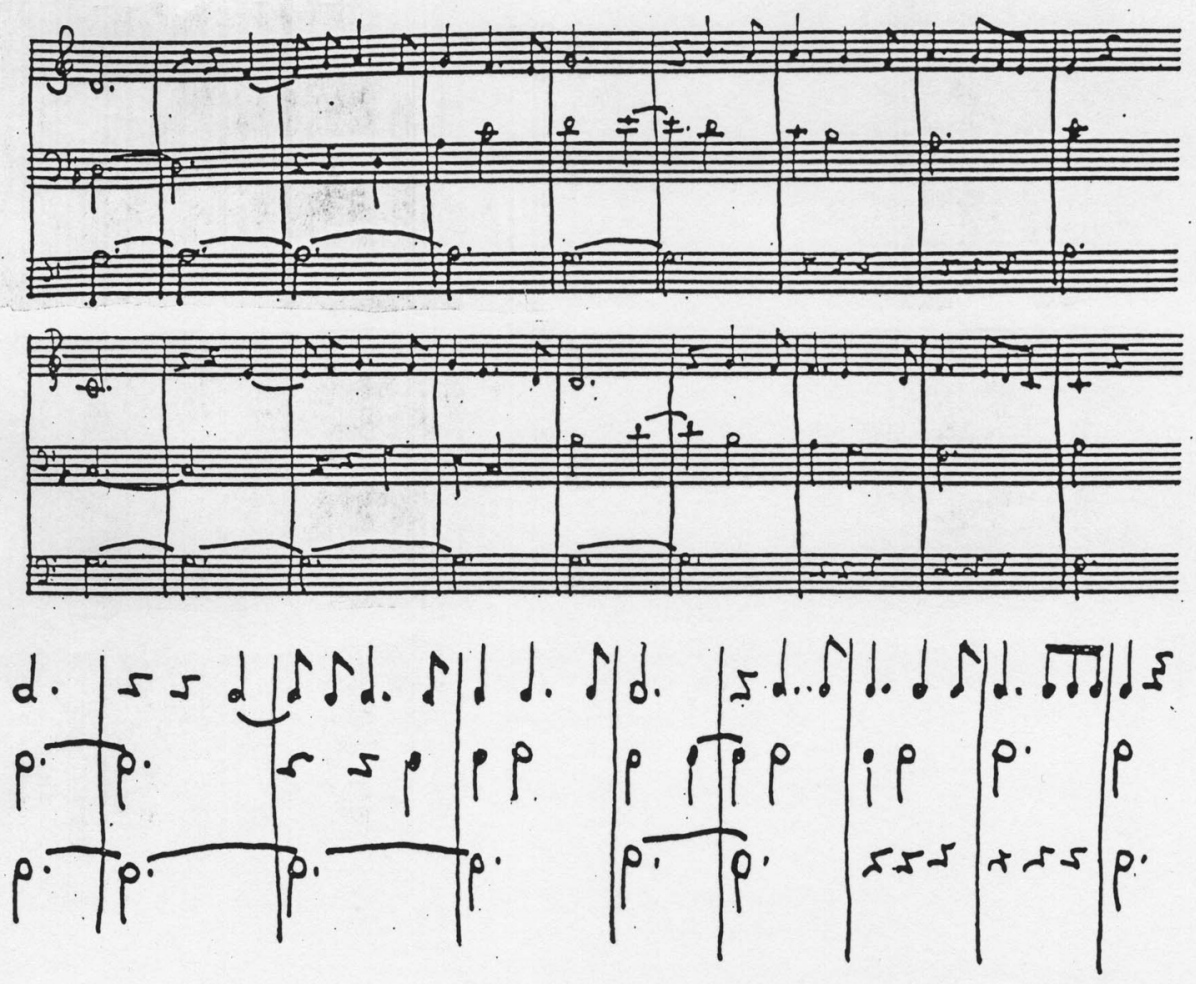

Figure 1: Motet by Dunstable, (Bukofzer, 1942, p. 179)

Specifically, the condition mentioned above demands the preservation-in analogous position in other cells of the music - of the time ratios between tempos that are contained in a basic cell of the composition, or in other words, a talea. From the mathematical point of view and in light of Ridell/Fowler's interpretation of ratio mentioned above, this requirement could be interpreted as the establishment of a proportion between different cells of the music in order to imitate an established pattern - the transference of an inherent abstract standard of a basic context by means of proportions (analogia).

Here we have similar analogical parts of the music that are in the same ratios but are not equal, in the same way that ratios may not be made equal to one another, but may be brought into relation with one another by means of proportions in propositions. In other words, a certain cell of the composition 'is as' a talea in the analogous way that a ratio 'is as' another ratio in Euclid. Far from having an arithmetical connotation, ratio and proportion in such a context as well as the aforementioned considerations evince the diversity and indefiniteness in which such concepts were embedded. 


\section{FROM DISCRETENESS TO CONTINUITY: THE DIVISION OF THE TONE}

Despite the continuing popularity of Euclid's theories of ratio in the late Middle Ages as well as the limited influence of Oresme's treatment of ratios in mathematics up to the beginning of the 16th century, it seems that nearly one century after Algorismus proportionum and De proportionibus proportionum irrational numbers and/or incommensurable magnitudes were arising in musical contexts, where previously the sound produced by such ratios had not considered music. The evidence suggests that it occurred for the first time with Nicholas of Cusa, who asserts in his Idiota de Mente of 1450 that the musical half-tone is derived by geometric division of the whole-tone, and hence is defined as an irrational number. Nicholas was the first to formulate mathematically a concept that is the cornerstone to the comprehension for the equal temperament proposed in the work of the high Renaissance music theorists Faber Stapulensis and Franchino Gafurius published half a century later (Goldman, 1989, p. 308). Cusa's work also influenced the German theorist and cossist Henricus Grammateus (Heinrich Schreyber) in his Ayn new kunstlich Buech, which is a tuning handbook considered essential in the development of equal temperament. Cusa was at the University of Padua between 1417 and 1423, where he studied with the mathematician and music theorist Prosdocimus de Beldemandis, who attacked Marchetto's division of the whole tone into 5 equal parts in his Tractatus musicae speculative published in 1425 .

Faber Stapulensis demonstrated that halving an epimoric interval, impossible by linear section, could easily be accomplished by geometry. First published in 1494, Faber's Elementalia musica contains for the first time a geometrical construction 'illustrating' not only Cusa's geometric division of the tone but the division of fourth, fifth and octave using geometrical mean (figure 2). Since no other author before Faber aside from Nicholas of Cusa mentioned the geometric division of the tone, Goldman proposed that Cusa's suggestion in the Idiota de Mente was Faber's source (Goldman, 1989, p. 324). 


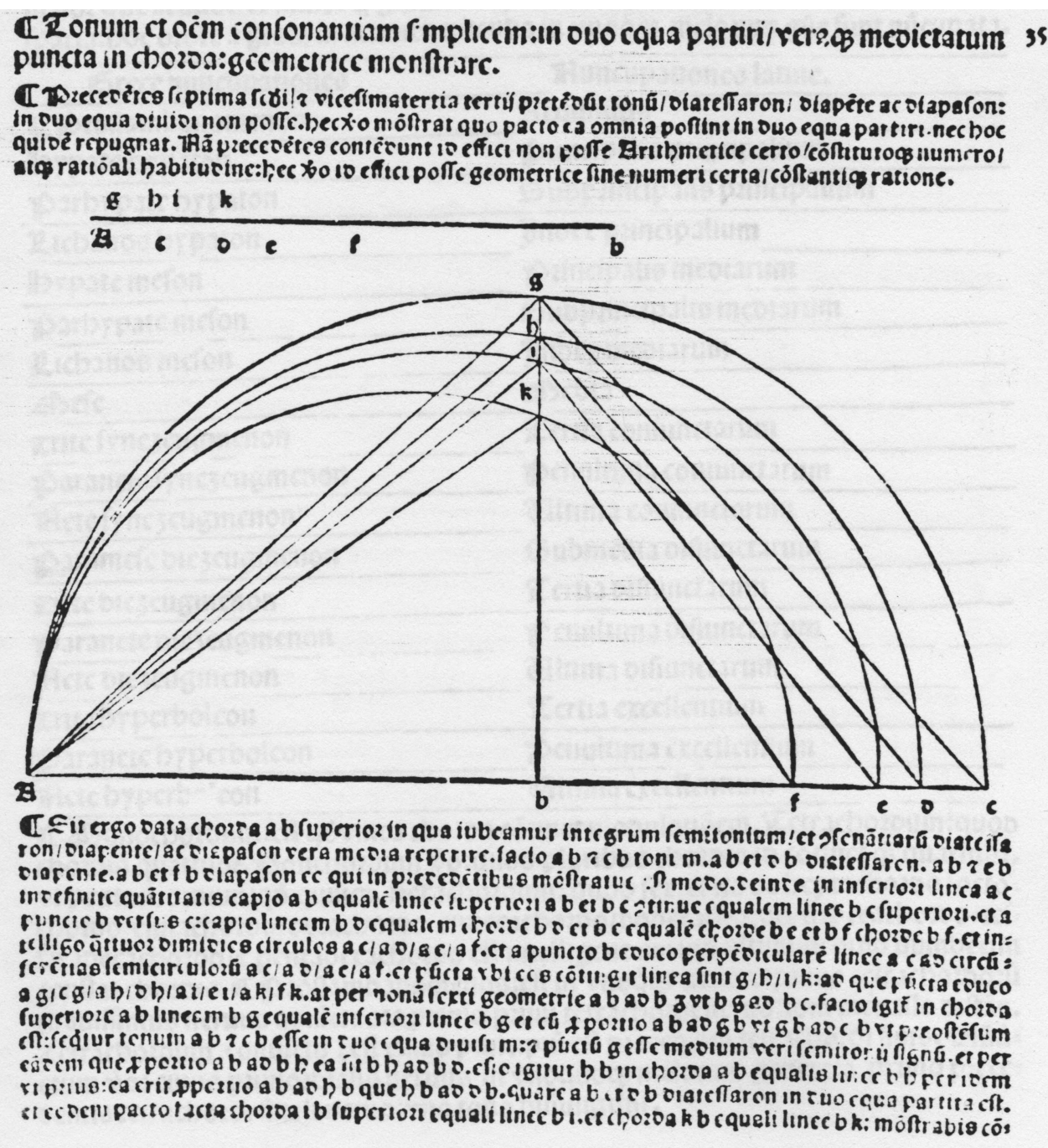

Figure 2: Geometric division of superparticular intervals by Faber Stapulensis, 1494

Grammateus (1492-1525/6) was a German mathematician, who matriculated in Vienna in 1507 and studied at Cracow between 1514 and 1517 returning then to Vienna. Concluded in 1518 and published in 1521 in Nuremberg, Grammateus' 'Ayn new kunstlich Buech...' presented, as an second part, music as the first application of the course of reckoning. Entitled Arithmetica applicirt oder gezogen auff die edel kunst Musica (figure 3), such an appendix presents the division of the tone in two equal semitones using Euclidean method for finding a geometric mean proportional. 


\section{Ilritbmetica applicirt ooer ${ }^{-01}$ gesogêauffoie ded Bunfentufica,}

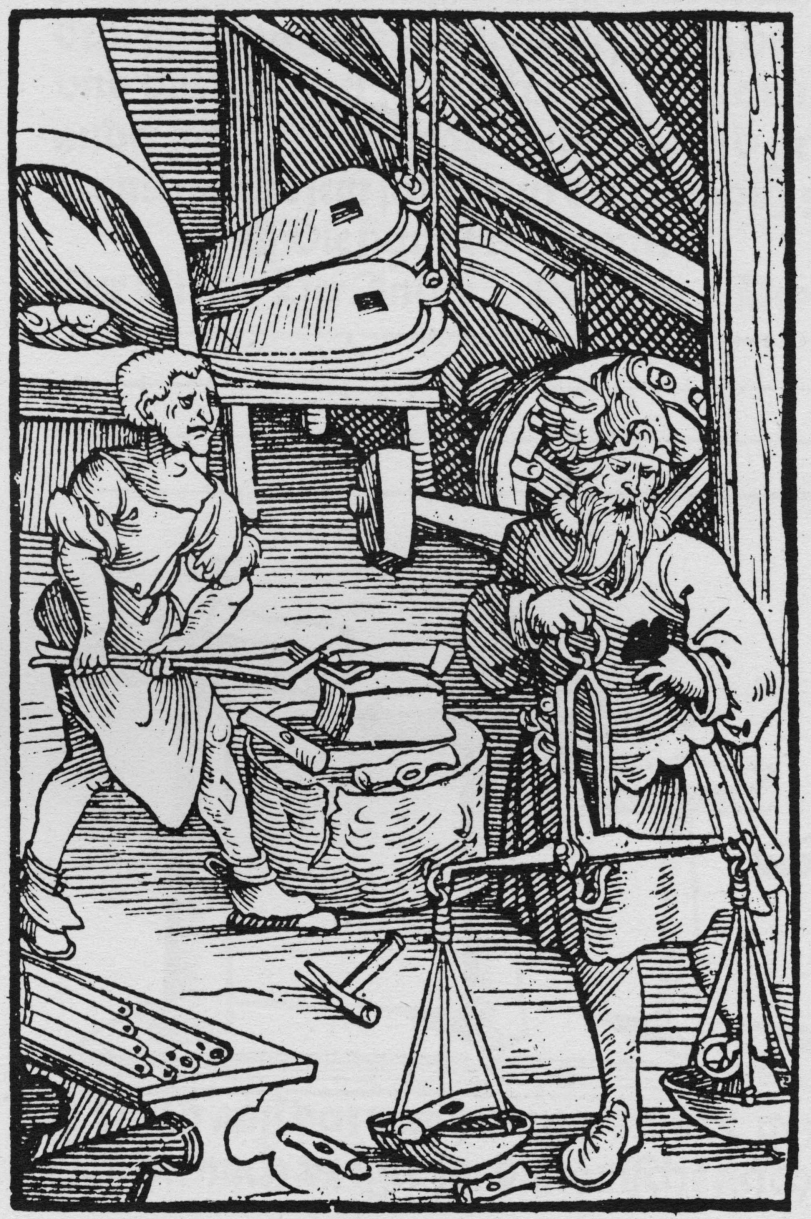

Figure 3: First page of Arithmetica applicirt oder gezogen auff die edel kunst Musica, 1521

In order to carry out the geometrical division of the whole-tone, Grammateus sketched a semicircle, whose diameter he divided in 17 equal parts. From the left extremity of the given diameter to the right, he drew a perpendicular from the ninth correspondent division up to the intersection with the semi-circle, which provided the geometric mean of the whole tone, namely, the square-root of the ratio 9:8 (figure 4). Grammateus may have owed this construction to Stapulensis (Barbour, 1933, p. 298). 
Gifynsufareeibent bie fentitontia mirtort.

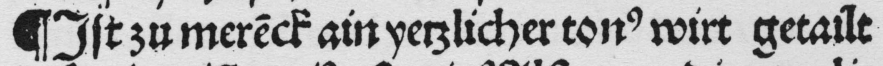

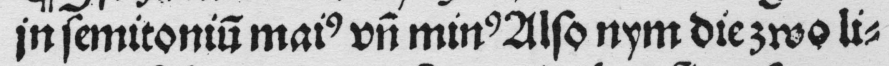
inten rodd che tonum gebent wno thue fie 3 ufaments

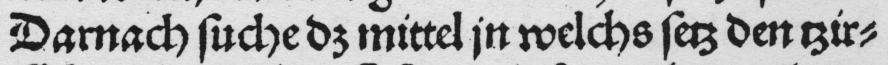
cFel mit oem ainent fuf vonto fpant bent andern bis ant bas enot Der linient oud fheyb ain balbe

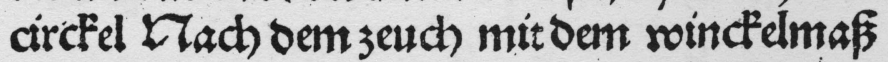
ain lintent vom punct rou oie 3 roo linien feir 3 us famen gethont bif 34 bem bogen ober balbent circtel / vmto bie felbigh lentg itym mit Dem circtel

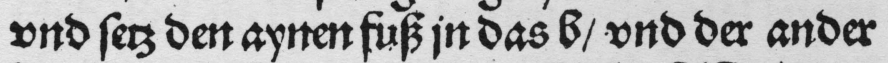

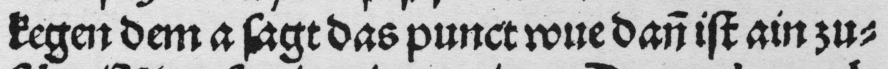
foh:eibe der fentitentium minus (Darnad) mad 3 wey Eleyn balb circtel die richt auf fim avno B 3etrd Sar uber ain fayten fo iff alle ointy Bereit.

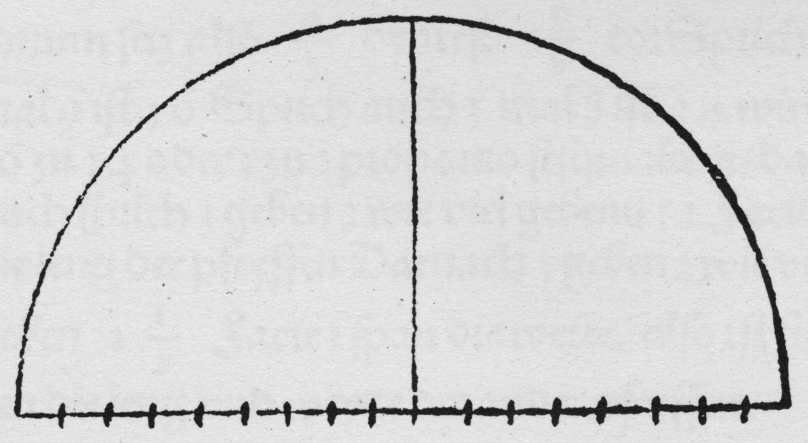

Figure 4: Geometric division of the tone by Grammateus, 1521 (Bywater, 1980, p. 88)

Unusually for theoretical treatises, Grammateus defined the operation additio applied to fraction—Bruchen—or to ratio—Proportio ${ }^{3}$ —explicitly for arithmetic and music, respectively. In the Arithmetica applicirt..., the German theorist defined 'additio' of 'proportio' - the latter previously defined-in order to apply such a concept to the 'addition' of 'proportio' 4 of the hammer (figure 5). Interestingly, he asserted in such a definition that the 'addition' of 'proportio' is as multiplication of fractions-defined in the first part of the work, namely, gleych multiplication in Bruchen (Bywater, 1980, p. 84), which not only corroborates the presence of traces of

\footnotetext{
3 ratio in modern language

4 multiplication of ratios
} 
the aforementioned similarities — in the case, in the realm of terminology and structure - almost two millennia after its origin but also evinces the persistence of these mixed traditions in the treatment of ratios, with the difference that it is now presented as an attempt at reconciliation.

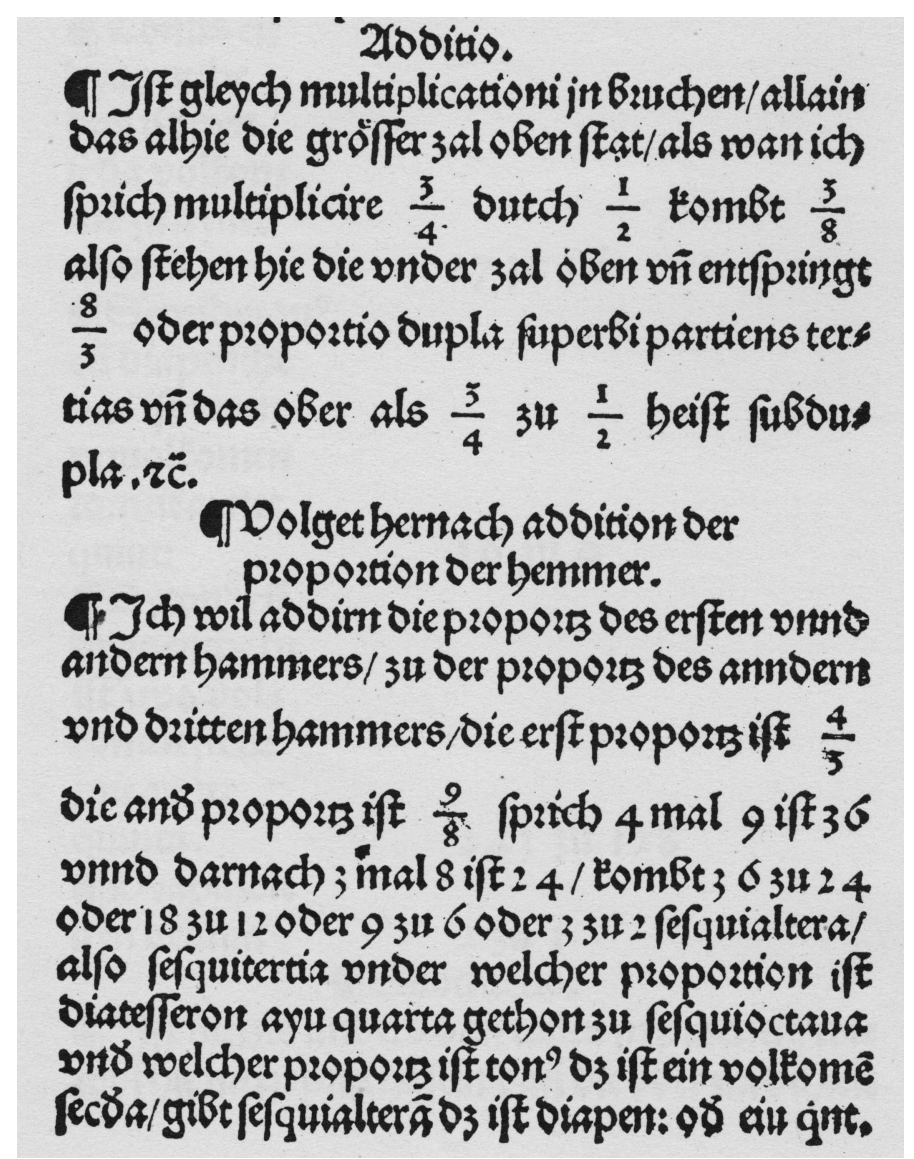

Figure 5: Additio in Arithmetica applicirt oder gezogen auff die edel kunst Musica, 1521 (Bywater, 1980, p. 84)

Together with the theorists mentioned above, the seed of transformation planted by Cusa took root in important theorists who establish an authentic tradition of the use of geometry to solve problems in theoretical music — a practice which, motivated initially by the problem of the division of the tone, then tacitly introduced the arithmetization of theories of ratio in musical contexts (if it was not in fact the case that the arithmetization itself led to the solution of the problem of the division of the tone). It is worth commenting at this point that the late 15 th and early 16 th centuries witnessed not only the strengthening of the acceptance of the practical Arabic/Hindu algebra, but also the humanist translation of the Greek mathematical corpus into Latin-Euclid, Archimedes, Ptolemy, Diophantus, etc.- - and thus prompted European mathematicians to begin reasoning in Greek mathematical terms again, equipped now, however, with the growth of the interaction between arithmetic and both algebra and geometry-a situation that would inevita- 
bly awaken interest in number theory. The Pythagorean crisis concerning incommensurable magnitudes increased the distance between arithmetic and geometry, the former becoming from that moment on exclusively a matter of discrete quantities and the latter a matter of continuous quantities - a differentiation that is still clear in theoretical musical treatises of the 16th century. While they make difficult the reconciliation of the arithmetization of geometry with the idea of number as real in modern sense, such dynamics encountered at this moment a fertile ground for catalyzing the emergence of an arithmetic theory for ratios.

Nevertheless, the matter is not so simple. The entire movement towards rescuing Greek thought at the same time brings side-effects in the arithmetization of theories of ratio. In the attempt to reestablish the ideals of classical civilization through the restoration of classical texts, Humanist scholarship in the 16th century also undertook the hard task of uncovering the authentic Euclid's The Elements. Seeking to eliminate the corruptions in a such a work, which include among other things the aforementioned interpolated arithmetic features introduced by Campanus, they consulted the ancient Greek sources directly, which resulted in the first translation of Euclidean corpus directly from Greek by Bartolomeo Zamberti in 1505 in Venice. Such a task strengthened even further the geometric/musical and non-arithmetical character of ratios, evincing again the epistemological tension under which the theories of ratios were treated and existed throughout Middle Ages and Renaissance.

Interestingly, the beginning of 16th century saw also at the University of Paris the triggering of interest for Oresme's treatment of ratios of ratios with George Lokert and Álvaro Thomas. Such a fact reinforces the plausibility of the existence of important influxes of mathematical knowledge via music at this period, such as for instance the catalyzation of the arithmetization of theories of ratio in mathematics motivated by necessity of dividing the whole-tone and more generally by the emergency of equal-temperament, whose systematical evidences gets stronger from the middle toward the end of 15th century and beginning of 16th century.

\section{ERASMUS OF HÖRITZ}

In the context of recovery of the interest in ancient texts and, not unrelated, of the use of geometry to solve problems in theoretical music, the Bohemian mathematician and music theorist Erasmus of Höritz ${ }^{5}$ emerged as one of the German humanists of the early 16th century most articulate with musical matters (Palisca, 1994, p. 151). Erasmus went back to the Greek sources

\footnotetext{
5 I am very grateful to Prof. Claude Palisca for calling to my attention the importance of Erasmus of Höritz for my work, and for suggesting and providing me with important information and bibliographical references.
} 
of the doctrines of Boethius, communicating to musical readers an important fruit of the revival of interest in ancient texts (Palisca, 1994, p. 158). Erasmus was the first in the Renaissance to apply explicitly Euclidean geometry to solve problems in music theory. Based strongly in Euclid's The Elements and at the same time following the tradition of De institutione musica of Boethius, his Musica was written probable between 1504 and 1508, where Horicius used geometry in different ways in order to solve musical problems, applying such a subject for instance to music intervals. He aimed to emulate the method of the ancient Greeks in applying mathematics to study sense phenomena (Palisca, 1995, p. 696), following in particular the method of the ancient Greek Aristoxenus of Tarent, a disciples of Aristotle, in applying geometry to music.

The most characteristic of his Musica is the exhaustive application of the theorems of Euclid's Elements. It is this comprehensive geometrical work rather than the summary arithmetical and musical books of Boethius that serves Erasmus as his starting-point and model (Palisca, 1994, p. 158). In his Musica, Erasmus presented the division of superparticular ratios and particularly of the whole tone-mathematically of $9: 8$ - in chapter seventeenth. He did it first by constructing this ratio with huge numbers, assured by proposition 18 of Book VII of The Elements, which asserts, apart from nomenclature, that $a: b:: m a: m b$. Erasmus used particularly the ratio $34828517376: 30958682112$ (figure 6) which is nothing but anachronously $386835264 \times 9: 386835264 \times 8$, that is, he applied the proposition 18 mentioned above applied to $a: b$ and m equal to $9: 8$ and 386835264 , respectively. He anticipated indirectly the notion of decimal fractions inasmuch as his idea is in favor of precision for the greater the terms of the equivalent ratio, the more accurate the integer between such terms that better approach the proportional mean. Nevertheless, he avoided the latter operation. 


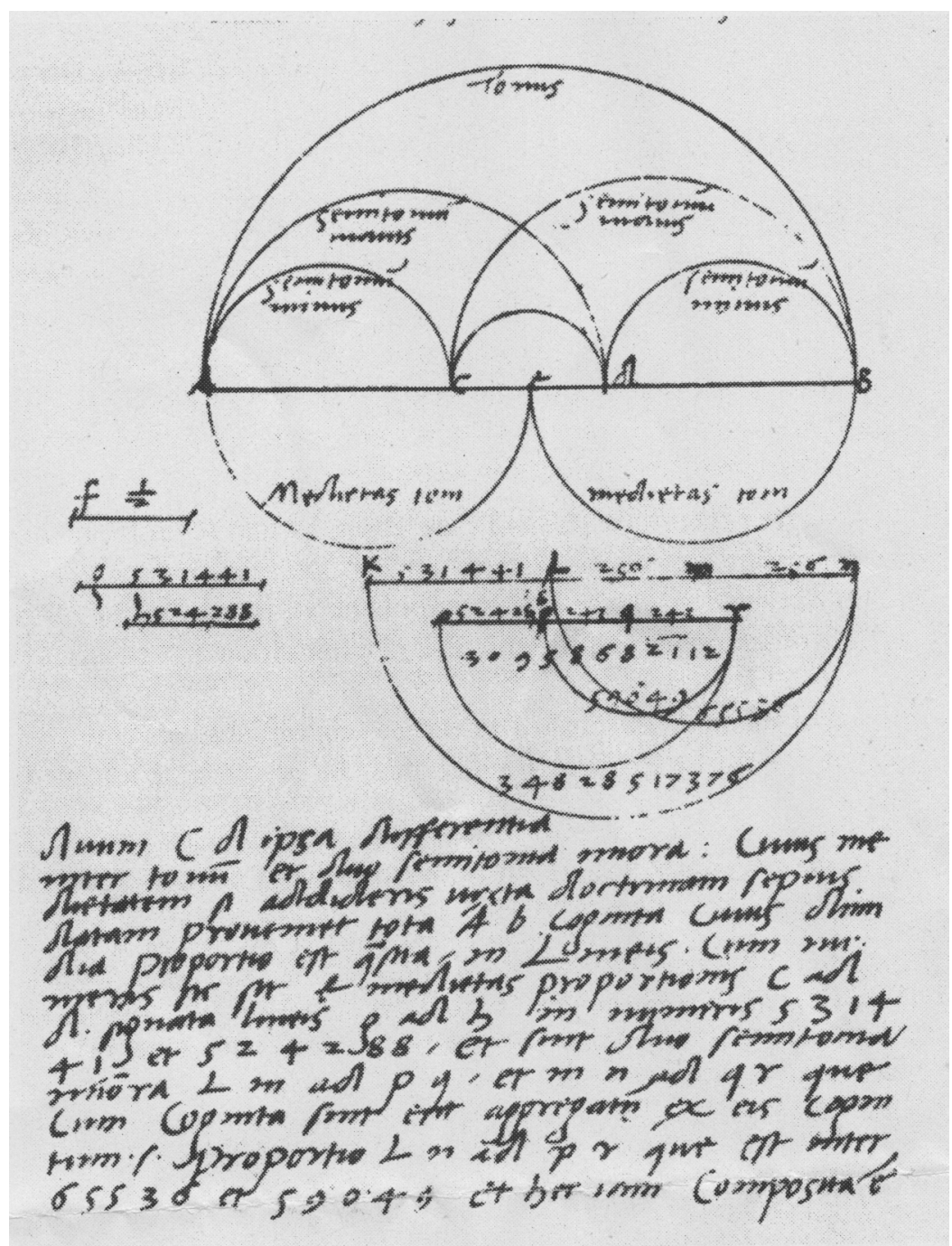

Figure 6: Musica, Erasmus Horicius, Biblioteca do Vaticano, S Regina lat.1245, fol. 66v

Rather, he manipulated this enormous ratio by making use of a sequence of Pythagorean-Boethian ratios for the minor and major half tone as well as for the Pythagorean comma and its halves (Popovic, 1988, p. 7), camouflaging his procedure as strictly musico-theoretical speculation in a Boethian fashion. The reason why he did not carry out this procedure explicitly by means of the well-known Euclidean method of finding the geometric mean proportional present in the proposition 13 as well as in the corollary of proposition 8, Book VI of The Elements (Heath, 1956, p. 216, 211) is not clear. Taking into account his exhaustive application of the theorems of Euclid's The Elements, he was certainly acquainted with such propositions. Moreover, some year before the preparation of the Musica, Faber Stapulensis had already succeeded in dividing superparticular ratios. Independently of his awareness either of Euclid's and/or, less probably, of the Faber's geometric construction, it seems that the Erasmus's choice is an attempt 
to establish a compromise between the authority he bestowed on Boethius and his acquaintance with the intellectual movement to revive Greek sources and strengthen algebra that I have already mentioned.

At this point, it is worth asking what was Erasmus's conception of ratio. Did he conceive of it as a number? If he had divided the whole-tone explicitly through geometric construction, he would be conceiving ratio albeit unrigorously as a real number, that is, he would be identifying ratio with the real line, which would go against Boethius's tradition in dealing with ratio in musical context. It must also be taken into account, as emphasized throughout this survey, that theories of ratios in mathematics at this moment were still of an indefinite nature. On the other hand, if he used geometry exhaustively, it would be natural to conceive of continuous magnitudes as underlying musical intervals. It seems then that he tried to find the square root, of which he felt the indispensable need, by using 'allowed' operations according to the theories of ratios current at this time and/or in music.

Taking 9:8 with huge numbers, he may have attempted, in front of the situation mentioned above, to compromise such aspects in order to halve the whole-tone with an accuracy as precise as possible according to the greatness of the factor by which he multiplied the numbers involved in the ratio. Being structurally analogical to establishing more places after the decimal point, such a process provided approximations as precise as possible of the desired square root. Apart from nomenclature, it is equivalent to finding, from a given number ' $p$ ' close to the square root ' $s$ ', a term of a sequence $a_{n}$ such that $\left|a_{n}-s\right|<|p-s|$, that is, such that its distance to the square root is smaller than the distance of $p$ to the square root, which conveys the idea of convergence. Taking into account the resources available as well as the context in which the problem was inserted, Erasmus' procedure was quite ingenious, anticipating decimal fractional and perhaps even bringing together the idea of sequence and its convergence.

Such an interpretation situates Erasmus in a special position in the process of arithmetization of ratios, where he may have stimulated important advances. His contribution can be seen thus as an essential step on the long way from Eudoxus's theory of proportion-preserved in book V of Euclid's The Elements - to the laying of foundations for the real number system in 19th century by Weierstress, Cantor, Mèray, Dedekind, and many others (Popovic, 1988, p. 4).

It is worth commenting that Grammateus attended three of same universities as Erasmus: Erfurt, Cracow and Vienna, but about ten years later. The two may have known each other in Vienna (Palisca, 1994, p. 161), what make possible an influence of the latter over Grammateus concerning the division of the tone. The change of view in Erasmus finds parallels in the change of techniques in dividing the monochord, which gives evidence at this time of mixed methods that 
make use of compounding and proportional means. Such changes seem to constitute a substantial change in the conception underlying theoretical music, that makes explicit a new perspective on classical problems such as the division of the superparticular intervals, impossible according to Boethius, whose opinions enjoyed a great influence in theoretical music in the Middle Ages.

The end of the 15th and the beginning of the 16th century thus witnessed a significant extension in the spectrum of techniques used in theoretical music, which begin to include explicitly geometry, subsequently widely used, among the mathematical tools of solving problems - for instance, the division of the tone. Such a use goes beyond the needs of temperament and signified also a important change in the conceptions used by musical theoreticians of this period to deal with ratios. This change intensifies the conflict with the Pythagorean conception of music according to which only whole numbers and ratios of integers should participate of the discourse concerning theoretical music, thereby promoting greater interaction between arithmetic and geometry in a musical context.

\section{ARITHMETIZATION OF GEOMETRY IN IBERIAN RENAISSANCE MUSIC}

Still in this period, the University of Paris witnessed the presence of numerous Spanish mathematicians, an intellectual movement which resonated in the arithmetization of geometry in mathematical/musical contexts in Iberian Peninsula through important scholars like Pedro Ciruelo and Juan Bermudo.

One of the great mathematicians of Spanish Renaissance, Ciruelo studied philosophy, theology and mathematics at the universities of Alcalá de Henares and Salamanca and went to Paris in 1492 staying until 1502 (Lorente y Pérez, 1921, p. 272), when he had contact with Faber Stapulensis, who was a professor at the University of Paris at the end of 15th century. After a sojourn in Sigüenza and Zaragoza, he returned to Alcalá de Henares in 1510, where he published for the first time in 1516-reprinted several times-his greatest work Cursus quattuor mathematicarum artium liberalium, which is basically a version of Faber's Elementalia musica with brief commentaries. Its musical part consist of a theoretical treatise, unlike the great Spanish musical theorists of 16th century, strongly based on the Boethian tradition comprising theoretical accounts unrelated to practice, which contains precisely the aforementioned geometric division of the whole-tone presented by Faber. 
Furthermore, Ciruelo employed in the book of Geometry the terminology addere and coniungere to express compounding ratios according to the musical tradition mentioned above and curiously undertook the subtraction reciprocally according to such a tradition in the seventh conclusion of third book of Geometry (Ciruelo, 1526). Such an operation corresponds in modern nomenclature to subtracting $c: d$ from $a: b$ and finding an intermediary term $\mathrm{m}$ such that $m: b:: c: d$, thus transforming the original task into subtracting $m: b$ from $a: b::(a: m)(m: b)$, what results immediately in $a: m$, as a natural extension to the operation of compounding ratios mentioned above. Although the Spanish mathematician revealed a tendency to arithmetization of geometry in his division of the tone, the operation mentioned above evinces at the same time traces of the similarities between mathematics and music in his treatment of ratios without arithmetical connotation in a context of theoretical geometry, what confirm the indefiniteness concerning nature of ratio at this time.

The exchanges between theorists of music and mathematicians of this epoch is also remarkable. Salinas's exposition of Book I of the De musica libri septem, published in Salamanca in 1577, is quite similar to the work of Ciruelo, who in turn was professor at the University of Salamanca from 1538 until his death in 1548. Concerning the repercussion of Paris' intellectual movement in Iberian culture, it is worth commenting that Salinas dedicated chapter 29 of book IV of $D e$ musica libri septem to an critical evaluation of Faber Stapulensis' work. Containing a through exposition of Neo-Pythagorean number theory in order to provide the Renaissance musician with the mathematical tools necessary for the study of music theory (Daniels, 1956, p. 5), the aforementioned Book I was thus probably influenced either by Faber's Elementalia musica or by Ciruelo's Cursus quattuor mathematicarum artium liberalium, if we also take into account Ciruelo's sojourn at the University of Salamanca in his ten last years of life, as well as Salinas (1513-1590) stay there first as student and then at the last period of his life.

The influence of scholars of the University of Paris in Iberian Peninsula concerning the use of geometry in theoretical music manifested also in Juan Bermudo (1510-1565). In book IV of his Declaración de Instrumentos musicales (1555), Bermudo presented a division of the wholetone in a section entitled Como el tono se puede dividir por medio (figure 6). 


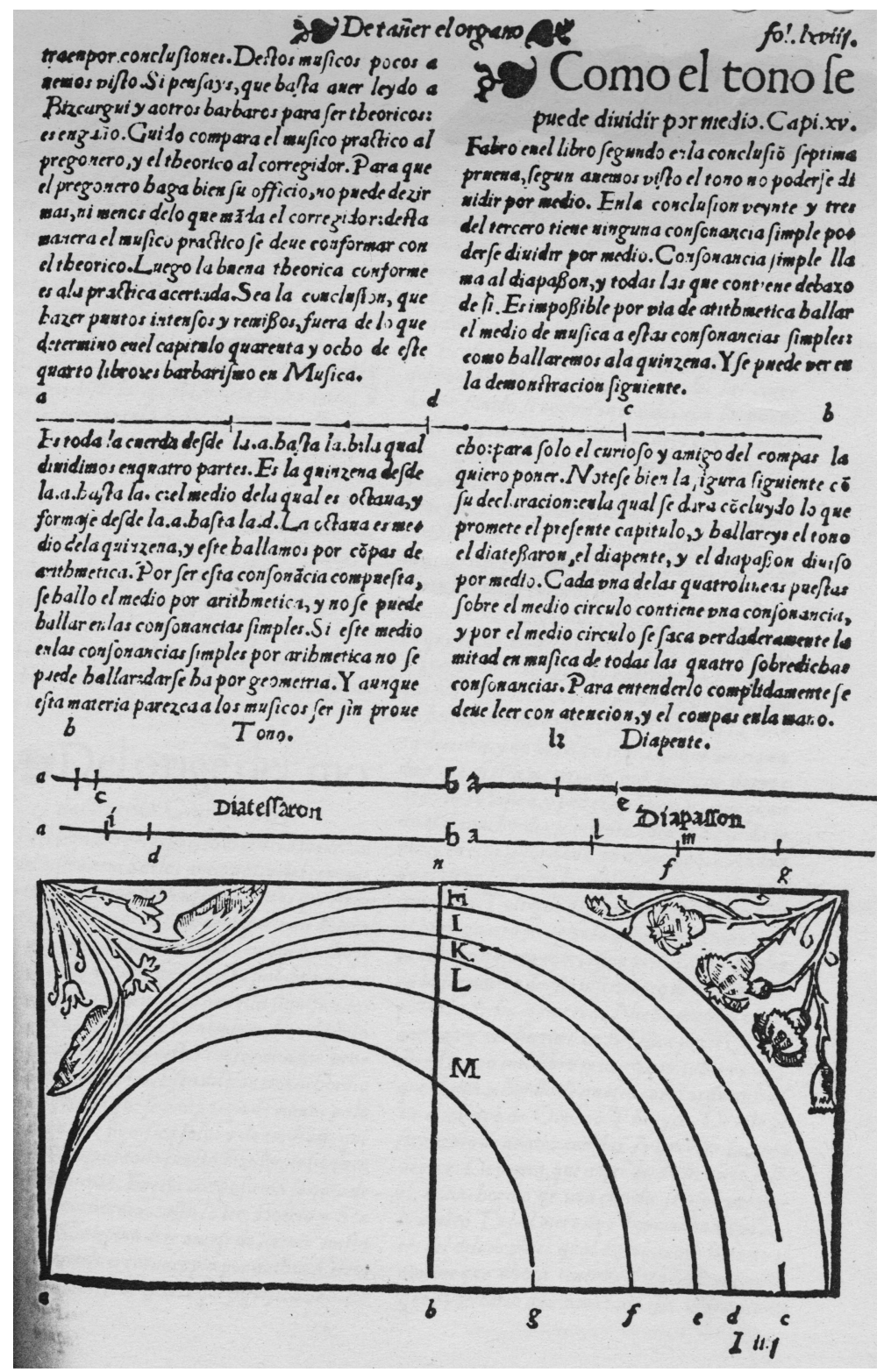

Figure 7: Geometric division of the tone by Bermudo, 1555 (Bermudo, 1555, fol. 1 xviii)

At the beginning of this section, Bermudo asserted the impossibility of division of the wholetone alluding to the seventh conclusion of book II of Faber Stapulensis. Just after, he generalized such a affirmation by proposing that all simple consonances, expressed by superparticular ratios, cannot be equally divided by means of arithmetic. This last constraint prepared the way for the statement that Si este medio en las consonancias simples por arithmetica no se puede hallar darse ha por geometria. Y aunque esta materia parezca a los musicos ser sin provecho, para solo el curioso y amigo del compas la quiero poner ${ }^{6}$ (Bermudo, 1555, fol. 1 xviii). Although the use of ratios in geometric context is not explicitly assumed in such a musical theo- 
retical treatise, it leads to the arithmetization of theories of ratio in musical contexts, which eventually brings about the meeting between arithmetization of geometry and the conception the number as a continuum.

Juan Bermudo (1510-1565), in his Declaración de Instrumentos musicales (1555), and Henricus Grammateus (1492-1525), in the section Arithmetica applicirt oder gezogen auff die edel musica of his book Ayn new kunstlich Buech, made interesting modifications to the Pythagorean tuning (Barbour,1933). They probably carried them out under the influence of Faber Stapulensis, whose method of establishing a tuning showed originality, even though he did not apply it to any particular tuning system. Bermudo and Grammateus completed the Pythagorean tuning by dividing each tone of the diatonic scale into two equal semitones using the Euclidean method of finding the geometric mean proportional in the proposition 13 as well as in the corollary of proposition 8, Book VI of The Elements (Heath, 1956). In this way, the chromatic scale had ten equal semitones and two slightly smaller Pythagorean ones and this made their tuning quite close to equal temperament.

\section{CONCLUSION}

As we have seen, throughout the history of mathematics and theoretical music, ratio and proportions assumed different meanings with discrete or continuous natures in regard to geometry, music and/or arithmetic. Among such meanings, ratio can be seen as a tool of comparison by means of proportions, a musical interval, a fraction, a number, an invariant with respect to proportion, a common thread between distinct contexts with regard to proportions whereas proportion can be seen as a vehicle with which to compare ratios, an equality, a relation, a function etc. In such a constellation of meanings-not to mention the linguistic and philosophical spectrums - , this article has tried to bring out the understanding, from a musical perspective, of the evolution of the concept of ratio from the Greek term logos, which was more geometrical than arithmetical and was definitely not a number but a relationship between numbers or magnitudes, to the identification of ratio with number, that is to an informal idea of rational number.

It emphasized some peculiarities of the complex process of emergence undergone by arithmetical theories of ratios, giving special attention to the participation of theoretical music in it. The impossibility of closing the cycles of fifths and octaves in the Pythagorean tuning, which is generated fundamentally by the lack of existence of any solution to the problem of the equality of

\footnotetext{
6 If the middle of the consonance can not be found by arithmetic, it is possible to find it by geometry. And although such a matter seems to be without benefit, I want to pose it only for those who are friends of the compass.
} 
$(1 / 2)^{\wedge} n$ (n cycles of octaves) with that of $(2 / 3)^{\wedge} m$ ( $m$ cycles of fifths) for $m, n$ integers, introduces issues that would culminate with the appearance of other temperaments, especially in the late Middle Ages and Renaissance, when a broader range of techniques concerning operations with ratios played a crucial role. Among the thinkers that contributed to such temperaments, are Ramos de Pareja, Juan Bermudo (Ree Bernard, 1992), Henricus Grammateus, Francisco Salinas, the latter being the first to provide a precise mathematical definition of equal temperament (Barbour, 1953, p. 6).

Such temperaments make use for instance of mathematical procedures not found in music prior to this time, such as the proportional mean of epimoric ratios, i.e., $n:(n+1)$, in particular applicable to the division of the tone. These procedures, which were considered impossible in theoretical music, because there intervals were determined only by ratios of integer numbers, is the view taken for instance in proposition 3 of the second part of Sectio Canonis (Barber, 1991) or in proposition I of Book 3 of De Institutitone musica (Bower, 1989, p. 88), works of considerable influence in medieval treatises of music. Such a position begins to change in early 14 th century and was eventually systematically overcome in the early Renaissance through scholars like Nicholas of Cusa, Faber Stapulensis, Erasmus of Höritz, Henricus Grammateus, Pedro Ciruelo, Juan Bermudo and others, who proposed the equal division of tone by means of geometry, which leads to a better approach to equal temperament.

Nevertheless, taking into account that 12 decomposes in integer prime factors as $2 \times 2 \times 3$, the problem of equal temperament will eventually need not only the square root but also the cube root, which essentially reduces such a question to the problem of the duplication of the cube ${ }^{7}$ so-called Delean problem - which the ancient mathematicians were unable to solve and actually is impossible with ruler and compass. Such impossibility will culminated with the appearance of other methods involving parabolas and variant secants taken up again by theorists of 16th century, whose reflection in theoretical music contexts results in the use of the mesolabium-a mechanical device with sliding parallelograms, ascribed to Archimedes-as also a resource to solve problems in theoretical music by Renaissance theorists like Zarlino and Salinas.

Such a dynamics only strengthens the non-returning trajectory of theories of ratios concerning arithmetization and brings out the contributions of problems in theoretical music to the emergence of an arithmetical theory of ratio, which includes among other things the identification between ratio and number, between proportion and equality and between compounding and multiplication, a conception definitely inevitable for the theoretical foundation by means of which such a musical problem is capable of being solved. The

\footnotetext{
7 To find the cube root of $a$ is equivalent to finding a cube with the double of the volume of that whose edge is $a$.
} 
appearance of the 'logarithm' at the start of the 17th century also allowed a more comprehensive mathematical understanding of 'equal temperament'. Both concepts were in a way already anticipated by Aristoxenus (4th century BC), who, in his discussion of the ear as the sole judge of correct pitch, describes scales with half tones, fourth tones etc., as well as an integer tone occupying 12 equal parts-notions which find no epistemological resonance with the mathematics of his time. Interestingly, the terminology used by Euclid is reflected even in Napier, who employs the word logarithm-logos, ariqmos-(Tannery, 1915, p. 71), which could mean the number of times a ratio is 'added', or equivalently the number of times an interval is subjoined.

Therefore, we started from a non-arithmetical theory that presumably originated in the Pythagorean treatment of music-theoretical tendency, whose inherent aforementioned similarities established an authentic Diaspora throughout the Middle Ages up to the Renaissance, which infiltrated different contexts of theoretical mathematics and music and which ultimately had to abandon its nature under pressure from musical theoretical needs. In fact, we have come full circle. In this entire process one can detect important peculiarities and/or components which actually contribute to the unusual nature of such a remarkable process. Among them, ratios move from a discrete and qualitative nature, in which they were not comparable, to a continuous and quantitative one, in the context either of rhythm or of pitch, where they are subordinated to a mathematical order of values. In parallel and not unrelated, such dynamics gradually brought together number and ratio, proportion and equality, compounding and multiplication, now also semantically and not only by virtue of structural similarity.

We may even say that the theory of ratio and proportion first borrowed terminology and operations from musical contexts and was perhaps even the first context in which such concepts appeared. The expansion of the use of ratio-including the need for systematization of equal temperament - over time as well as the growth of mathematics-with the advent of algebra, for instance-led to the adoption of more abstract mathematical structures which bore a closer similarity to ratios. Such a conjunction, which brought together the aforementioned identifications, would eventually culminate in the arithmetization of geometry as well as in the emergence of the concept of real number.

Also parallel is the extension in the spectrum of techniques used in theoretical music, particularly concerning division of the monochord, which come from diatonic divisions made up of superparticular proportions applied to such an instrument by means of a compass and which begin to include as an extension of this technique in 15th century mixed methods of adding chromatic semitones to a diatonic division making use of compounding and proportional meansin the first instance, square roots - at the same time, in order to approach equal temperament, 
an approximation which would eventually encounter its precise theorization in the following century, inasmuch such an accurate mathematical systematization demands the indispensable use of the cube root, infeasible without other resources besides ruler and compass.

Inside such a circular dynamics, we may perhaps also be able to detect a remarkable kind of "cross-analogy" between theories of ratio in mathematics as they developed in the period between the classical period and Late Antiquity and theories of ratio in music as they developed in the period between the late Middle Ages and the Renaissance. Whereas the former was detached partially from a geometrical theoretical nature in mathematics stemming from the classical period and came to assume an arithmetical practical nature in late Antiquity, the latter was detached partially from an arithmetical theoretical nature in music in late Middle Ages according to a Platonic-Pythagorean tradition and came instead to assume a geometrical practical nature in Renaissance.

\section{BIBLIOGRAPHY}

Barbera, A. The Euclidean Division of the Canon. Lincoln: University of Nebraska Press, 1991.

Barbour, J.M. "The Persistence of the Pythagorean Tuning System." Scripta mathematica, 1933, 1, pp. 286-304.

- Tuning and Temperament. A Historical Survey. East Lansing: Michigan State College Press, 1953.

Barker, A. ed. Harmonic and Acoustic Theory. Cambridge: Cambridge University Press, 1989.

Bower, Calvin M. and Palisca, Claude V. eds. Fundamentals of Music. Anicius Manlius Severinus Boethius. New Haven \& London: Yale University Press, 1989.

Bukofzer, Manfred F. "Speculative Thinking in Medieval Music." Speculum: a journal of medieval studies, 1942 (April), 17, pp. 165-80.

Bywater, M.F. ed. Heinrich Schreiber. Ayn New Kunstlich Buech...1518. London, Tokyo: Scolar Press, Yushodo Press, 1518, 1980.

Ciruelo, Pedro. Cursus Quatuor Mathematicarum Artium Liberalium: Quas Recollegit Atque Correxit Magister Petro Ciruelus. Alcalá:, 1526.

Crosby, H.L. Thomas Bradwardine His Tractatus De Proportionibus. Its Significance for the Development of Mathematical Physics. Madison: The University of Wisconsin Press, 1955. 
Crubellier, Michel and Hidber, Thomas. "Analogie (1. Philosophisch)," H. Cancik and H. Schneider, Der Neue Pauly: Enzyklopädie Der Antike; Altertum, Bd. 1: A-Ari. Stuttgart, Weimar: Metzler, 1996, 650-51.

Curtze, E.L.W.M. ed. Der Algorismus Proportionum Des Nicolaus Oresme. Berlin: S. Calvary \& Co, 1868.

Daniels, A. "Microtonality and Mean-Temperament in the Harmonic System of Francisco Salinas (Part I)." Journal of music theory, 1965 (Winter), 9, pp. 235-81.

Drake, Stillman. "Medieval Ratio Theory vs. Compound Medicines in the Origins of Bradwardine's Rule.” Isis, 1973, 64, pp. 67-77.

Ellsworth, O. B. “A Fourteenth-Century Proposal for Equal Temperament.” Medieval and Renaissance Studies, 1974, 5, pp. 445-53.

Fowler, D.H. "Anthyphairetic Ratio and Eudoxus Proportion.” Archives for History of Exact Sciences, 1981, 24, pp. 69-72.

- The Mathematics of Plato's Academy. A New Reconstruction. Oxford: Clarendon Press, 1987.

—. "Logos (Ratio) and Analogon (Proportion) in Plato, Aristotle, and Euclid," J. Petitot and R. Thom, Archive for the History of Exact Sciences. Genève: Ed. Patiño, 1989, 444-72.

Friedlein, G. ed. Anicci Manlii Toquati Severini Boietii. Frankfurt: Minerva G.M.B.H., 1867,1966 .

Goldman, David Paul. "Nicholas Cusanus Contribution to Music Theory." Rivista Internazionale di musica sacra, 1989, 10/3-4, pp. 308-38.

Grattan-Guinness. The Fontana History of Mathematical Sciences. London: Fontana Press, 1997.

Grattan-Guinness, Ivor. "Numbers, Magnitudes, Ratios, and Proportions in Euclid's Elements: How Did He Handle Them?” Historia Mathematica, 1996, 23, pp. 355-75.

Grosholz, E. “Some Uses of Proportion in Newton's Principia, Book I: A Case Study in Applied Mathematics." Studies in history and philosophy of science, 1987, 18, pp. 208-20.

Heath, Thomas Little. A Manual of Greek Mathematics. Oxford: Clarendon Pr., 1931.

Herlinger, Jan W. "Fractional Divisions of the Whole Tone.” Music Theory Spectrum, 1981, 3, pp. 74-83.

Ierodiakonou, Katerina. "Logos (1) Philosophisch," H. Cancik and H. Schneider, Der Neue Pauly: Enzyklopädie Der Antike; Altertum, Bd. 7: Lef-Men. Stuttgart [u.a.]: Metzler, 1999, 401-05. 
Katz, Victor. A History of Mathematics. An Introduction. New York: Harper-Collins College Publishers, 1993.

Lorente y Pérez, José Maria. Biografia Y Análisis Pura De Pedro Sánchez Ciruelo. Madrid: Publicaciones del Laboratorio y Seminario matemático, 1921.

Lowinsky, E.E. "Music in the Culture of the Renaissance." Journal of the history of ideas: a quarterly devoted to cultural and intellectual influences, 1954, 15, pp. 509-53.

McClain, E.G. The Pythagorean Plato. Prelude to the Song Itself. Stony Brook: Nicolas Hays, Ltd, 1978.

Oresme, Nicole and Grant, Edward (Hrsg.). "De Proportionibus Proportionem" and "Ad Pauca Respicientes". Madison, London: Univ. of Wisconsin Press, 1966.

Palisca, Claude V. "The Musica of Erasmus of Höritz," C. Palisca, Studies in the History of Italian Music and Music Theory. Oxford: Clarendon Press, 1994, 146-67.

—. "Horocius, Erasmus," S. Sadie, The New Grove Dictionary of Music and Musicians. London: Macmillan, Music-dictionaries; Sadie, Stanley, 1995a, 696.

Peden, Alison M. “'De Semitone': Some Medieval Exercises in Arithmetic.” Studi Medievali, 1994, 35, pp. 368-403.

Popovic, Igor. "Musica Erasmi Horitii Germani. Mathematics and Speculative Theory of Music in the Renaissance: A Case Study." not published, 1988, pp. 1-20.

Riddell, R.C. "Eudoxan Mathematics and the Eudoxan Spheres." Archive for the History of Exact Sciences, 1979, 20, pp. 1-19.

Santiago Kastner, Macario and Bermudo, Juan eds. Fray Juan Bermudo. Declaración De Instrumentos Musicales. Bärenreiter: Verlag Kassel und Basel, 1555, 1957.

Schechter, John M. "Aristoxenus," S. Sadie, The New Grove Dictionary of Music and Musicians. London: Macmillan, Music-dictionaries; Sadie, Stanley, 1995b, 591-92.

Sylla, Edith Dudley. "Compounding Ratios. Bradwardine, Oresme, and the First Edition of Newton's Principia," E. Mendelsohn, Transformation and Tradition in the Sciences. Essays in Honor of I. Bernard Cohen. Cambridge: Cambridge University Press, 1984, 11-43.

Szabo, Árpád. The Beginnings of Greek Mathematics. Budapest: Akademiai Kiado, 1978.

Tanay, Dorit. "Jehan De Meur's Musical Theory and the Mathematics of the Fourteenth Century." Yearbook for the History of Science, Medicine and Mathematics, 1993, 5, pp. 17-43.

Tannery, Paul. "Du Rôle De La Musique Grecque Dans Le Développement De La Mathématique Pure,” p. Tannery, Memoires Scientifiques. Paris: 1915, 68-87.

Werner, Eric. "The Mathematical Foudantion of Philippe De Vitri's Ars Nova." Journal of the american musicological society, 1956, 9, pp. 128-32. 